CLINICAL STUDY

\title{
Gamma knife surgery for patients with volumetric classification of nonfunctioning pituitary adenomas: a systematic review and meta-analysis
}

\author{
Yong Chen*, Zhi Feng Li*, Fei Xiang Zhang, Jian Xian Li, Lin Cai ${ }^{1}$, Qi Chuan Zhuge ${ }^{1}$ and Zhe Bao Wu ${ }^{1,2}$ \\ Department of Neurosurgery, Yueyang Second People's Hospital, Yueyang 414000, China, ${ }^{1}$ Department of Neurosurgery, First Affiliated Hospital of \\ Wenzhou Medical University, Wenzhou 325000, China and ${ }^{2}$ Department of Neurosurgery, Huashan Hospital, Fudan University, No. 12, \\ Wulumuqi Middle Road, Shanghai 200040, China \\ (Correspondence should be addressed to Z B Wu at Department of Neurosurgery, Huashan Hospital, Fudan University; Email: zhebaowu@fudan.edu.cn)
}

*(Y Chen and Z F Li contributed equally to this work)

\begin{abstract}
Objective: The aim of this study was to scrutinize the literature to determine the efficacy and safety of gamma knife surgery (GKS) for the treatment of nonfunctioning pituitary adenomas (NFPAs) with volumetric classification.

Methods: Electronic databases including MedLine, PubMed, and Cochrane Central were searched. The literature related to patients with NFPAs treated with GKS was collected. Eligible studies reported on the rate of tumor control (RTC), the rate of radiosurgery-induced optic neuropathy injury (RRIONI), the rate of radiosurgery-induced endocrinological deficits (RRIED), and other parameters.

Results: A total of 17 studies met the criteria. Based on the tumor volume, NFPAs were divided into three groups: the RTC of group I (93 patients) with tumor volumes $<2$ ml was $99 \%$ (95\% CI $96-$ $100 \%$ ), the RRIONI was $1 \%(95 \%$ CI $0-4 \%$ ), and the RRIED was $1 \%$ (95\% CI $0-4 \%)$. The RTC of group II (301 patients) with volumes from 2 to $4 \mathrm{ml}$ was $96 \%$ (95\% CI 92-99\%), the RRIONI was 0 (95\% CI $0-2 \%)$, and RRIED was $7 \%(95 \%$ CI $2-14 \%)$. The RTC of group III (531 patients) with volumes larger than $4 \mathrm{ml}$ was $91 \%$ (95\% CI $89-94 \%$ ), the RRIONI was $2 \%$ (95\% CI 0-5\%), and the RRIED was $22 \%$ (95\% CI 14-31\%). There were significant differences in the RTC and in the RRIED among the three groups $(P<0.001)$, indicating that there were higher RRIED and lower RTC with the increase of tumor volume.

Conclusions: NFPAs, according to tumor volume classification, need stratification for GKS treatment. GKS is the optimal choice for the treatment of group II NFPAs. Patients with residual tumor volumes of $<4 \mathrm{ml}$ will benefit most from GKS treatment.
\end{abstract}

European Journal of Endocrinology 169 487-495

\section{Introduction}

Pituitary adenomas (PAs) represent $10-20 \%$ of all primary brain tumors (1). Clinically nonfunctioning PAs (NFPAs) make up approximately one-third of the PAs. Patients with NFPAs generally experience anterior pituitary hormonal deficits, visual loss, headaches, or less frequently, apoplexy. The goals of treatment are to achieve an adequate reduction of tumor volume and to preserve pituitary function.

The primary treatment for patients with NFPAs is pituitary microsurgery with a transsphenoidal or transcranial approach to achieve a rapid reduction of tumor volume and decompression of the optic apparatus. Incomplete resection because of regional tumor invasion into the surrounding structures (especially the cavernous sinus) may be associated with long-term recurrence rates in as many as $67 \%$ of the patients $(2,3)$. Although additional resection may be attempted for recurrent tumors, complete resection may remain difficult to achieve, and the risks associated with repeat surgery are greater than those for the initial operation (4).

Conventional fractionated radiotherapy (FRT) has been used after subtotal resection to reduce recurrence rates in patients with residual tumors or even in some patients after gross total resection $(2,5,6,7,8)$. FRT is thought to achieve tumor control rates of $90-97 \%$ and to significantly reduce the rate of recurrence with a reported progression-free survival of $75-90 \%$ at 20 years $(9,10,11,12)$. However, there is concern that FRT carries an increased risk of later toxicity. This is most commonly observed in the form of hypopituitarism, occurring in $30-88 \%$ of the patients at 10 years $(9,10,11)$. Hypopituitarism requires lifelong hormone replacement therapy with a significant impact on 
quality of life and has additionally been reported to be associated with increased respiratory, cerebrovascular, and cardiovascular mortality $(13,14,15)$. A less common finding is the development of radiationinduced neoplasia including meningiomas and glial tumors, with a reported incidence of $2 \%$ at 20 years (9). Furthermore, concern has arisen over the long-term neurocognitive impact of radiotherapy. Taken together, FRT provides adequate tumor control, but it poses a small risk of serious late-term sequelae.

Recently, gamma knife surgery (GKS) has been more commonly used in the management of PAs, either as adjuvant therapy after surgical resection or rarely as a primary treatment modality in select cases. It has improved upon standard FRT by enabling the delivery of targeted therapy in a single session, with a steeper dose gradient that minimizes irradiation to the surrounding structures. Theoretically, this provides increased precision with a minimization of toxicity, but we lack long-term safety and efficacy data for GKS with regard to optimal eligibility criteria and there is little information to assess the efficacy of GKS for the treatment of NFPAs of differing sizes and stages. However, the reports $(16,17,18,19,20,21,22,23,24,25,26,27,28,29$, $30,31,32)$ concerning the efficacy of GKS for the treatment of NFPAs are limited by small sample sizes, retrospective and nonrandomized study designs, heterogeneous patient populations, and varying definitions of outcomes. There is no multi-center meta-analysis summarizing the evidence regarding the knowledge of the efficacy and safety of GKS for the treatment of NFPAs with delineation of prognostic factors associated with poor outcomes for NFPAs that would help to formulate clinical practice guidelines.

In this study, NFPAs were divided into three groups according to the tumor volume (0-2, 2-4, and $>4 \mathrm{ml}$ ) at the time of GKS treatment. We wanted to clearly understand the efficacy and safety of GKS for the treatment of NFPAs through a systematic review and to gain reliable evidence to recommend eligibility criteria for the use of GKS for the treatment of NFPAs.

\section{Subjects and methods}

\section{Search strategy}

English literature papers published in MedLine, PubMed, and Cochrane Central databases from 1966 to January 2012 were systematically searched using the following terms: 'Gamma Knife surgery', 'radiosurgery', 'non functional pituitary tumors', 'nonfunctioning pituitary adenomas', 'nonfunctioning pituitary adenoma', 'non-function pituitary tumors', 'nonsecreting pituitary adenomas', 'non-secreting pituitary adenomas', and 'non secreting pituitary adenomas'. The 'related articles' function was used to obtain any relevant articles. Additionally, the references cited in the articles included in the analysis were reviewed for any other citations. The search was carried out independently by two members of the study team: $\mathrm{Y}$ Chen and Z F Li. Hand-searching was conducted using references from papers acquired using the computer searches.

\section{Inclusion/exclusion criteria}

Inclusion criteria included NFPAs for which GKS was carried out with or without surgical removal. These studies can provide the parameters of GKS for the treatment of NFPAs, such as the median/mean target volume, the tumor control rate, the actuarial tumor control rates (ATCRs) at 5 and 10 years, the rate of radiosurgery-induced optic neuropathy injury (RRIONI), the rate of radiosurgery-induced endocrinological deficits (RRIED), and the actuarial RRIED rates (ARIEDRs) at 2, 5, and 10 years. Eligible study designs included retrospective and prospective analyses.

Data from the articles obtained were extracted independently by two co-authors and reviewed by the corresponding author. Data collected from the articles included the number of patients, study design (retrospective vs prospective), the median follow-up period, the median/mean target volume, the tumor control rate, the ATCRs at 5 and 10 years, the RRIONI, the RRIED, the ARIEDRs at 2, 5, and 10 years, the median marginal radiation dose, and the median optic radiation dose. If articles could not provide the parameters directly, we indirectly extracted these parameters from the Kaplan-Meier curves of their articles. We contacted authors for missing data when needed. If no data were reported on a certain variable of interest, they were recorded as not available.

\section{Evaluation of the quality of studies}

This study adhered to the reporting guidelines of metaanalysis $(33,34)$ and used the GRADE approach to rate the quality of evidence (35). To assess the methodological quality of the studies, we determined items such as the period of inclusion of the patients, ascertainment of outcomes, follow-up protocol, definition of the decrease or increase in size, definition of pituitary insufficiency, radiosurgical technique, and calculation of tumor volume (36).

\section{Statistical analyses}

Weighted summaries were determined using metaanalysis models if a given result was reported by three or more studies. Tests for heterogeneity were carried out for each meta-analysis using the $I^{2}$ statistic $\left(I^{2}<25 \%\right.$ and $I^{2}>50 \%$ reflect small and large inconsistencies respectively). If the $Q$ value $(P>0.01)$ is not significant in the tests for heterogeneity, it indicates the heterogeneous nature of the research, so we used fixed-effects 
models or random-effects models. We used the Pearson's $\chi^{2}$ test for the comparative groups. The variance test was used to analyze the dose-related complications. The $\mathrm{R}$ meta package from the $\mathrm{R}$ statistical language for Windows and SPSS 12.0 were used to carry out these analyses (37). A $P$ value $\leq 0.05$ was considered to be statistically significant.

\section{Results}

\section{Search results}

The data abstraction process is shown in Fig. 1. The search identified 584 candidate references, of which 28 were studies deemed to be eligible $(16,17,18,19,20$, $21,22,23,24,25,26,27,28,29,30,31,32,38,39$, $40,41,42,43,44,45,46,47,48)$. We excluded six studies $(42,44,45,46,47,48)$ because the stereotactic radiosurgery was carried with a CyberKnife or linear accelerator. One study had few patients $(n=3)$ who underwent GKS (43). Additionally, we excluded four studies from this analysis because of poor quality assessment $(38,39,40,41)$.

\section{Study characteristics}

A total of 17 studies met the inclusion criteria, and the total number of patients included in this meta-analysis was 925 (summarized in Table 1 and Supplementary Table 1, see section on supplementary data given at the end of this article). These studies were longitudinal observational cohort studies, including prospective (seven studies) and retrospective (ten studies) designs. All patients with NFPAs had undergone GKS. These studies mainly analyzed the tumor control rate, the RRIONI, and the RRIED. NFPAs were divided into three groups according to the tumor volume at the time of GKS treatment, summarized in Supplementary Table 2. There were stratified data available for a total of

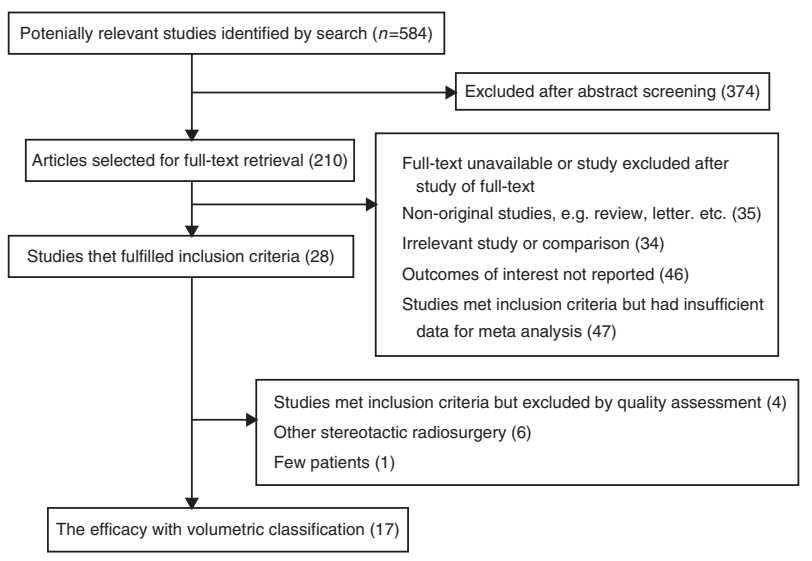

Figure 1 Study selection process.
93 patients with tumor volumes of $<2 \mathrm{ml}, 301$ patients with tumor volumes ranging from 2 to $4 \mathrm{ml}$, and 531 patients with tumor volumes $>4 \mathrm{ml}$.

\section{Meta-analysis}

Random-effects models and fixed-effects models were computed for the parameters according to the tests for heterogeneity, with probability values of $<0.01$ or above, as summarized in Table 2. The NFPAs were divided into three groups according to the volume of tumor tissue at the time of treatment: the tumor control rate of group I tumors (93 patients) with volumes $<2 \mathrm{ml}$ was $99 \%$ (95\% CI 96-100\%), the RRIONI was $1 \%$ (95\% CI 0-4\%), and the RRIED was $1 \%$ (95\% CI $0-4 \%)$. The tumor control rate of group II tumors (301 patients) with volumes from 2 to $4 \mathrm{ml}$ was 96\% (95\% CI 92-99\%), the ATCR at 5 years involving four studies with 166 patients was 91\% (95\% CI $88-93 \%)$, the RRIONI was $0 \%(95 \%$ CI $0-2 \%)$, and the RRIED was $7 \%$ (95\% CI 2-14\%). The tumor control rate of group III tumors (531 patients) with volumes larger than $4 \mathrm{ml}$ was $91 \%(95 \%$ CI $89-94 \%)$, the ATCR at 5 years involving five studies with 394 patients was 94\% (95\% CI 91-97\%), the ATCR at 10 years involving three studies with 299 patients was $80 \%(95 \%$ CI $72-87 \%)$, the RRIONI was $2 \%(95 \%$ CI $0-5 \%)$, the RRIED was $22 \%$ (95\% CI $14-31 \%$ ), and the ARIEDRs at 2,5 , and 10 years were $16 \%(95 \%$ CI $13-20 \%)$, $31 \%(95 \%$ CI $25-37 \%)$, and $49 \%$ (95\% CI $44-55 \%)$ respectively.

The pooled tumor control rate was 95\% (95\% CI $92-97 \%$ ). The pooled ATCRs at 5 and 10 years were $93 \%$ (95\% CI 90-95\%) and $80 \%$ (95\% CI $72-87 \%)$ respectively. The pooled RRIONI was $1 \%$ (95\% CI $0-3 \%)$. The pooled RRIED was $11 \%(95 \%$ CI $6-18 \%)$. The pooled ARIEDRs at 2, 5, and 10 years were $16 \%$ (95\% CI $13-20 \%$ ), $31 \%$ (95\% CI $25-37 \%$ ), and $49 \%$ (95\% CI 44-55\%) respectively.

\section{Pearson's $\chi^{2}$ test}

We used the Pearson's $\chi^{2}$ test to analyze the difference in the efficacy and safety of GKS among the three groups of NFPAs, summarized in Table 3. Significant differences in the tumor control rates were found among the three groups $(P<0.001)$, especially between groups II and III and between groups I and III, which indicated that there was a statistical trend in these inter-groups $(P=0.04)$. There was a statistically significant difference in the RRIED among the three groups $(P<0.001)$ and between two groups $(P<0.0125)$, which showed that the RRIED was more common with the increase in tumor volume. There was a statistically significant difference in the RRIONI between groups II and III $(P=0.003)$, but no significant differences were found between the other groups. 


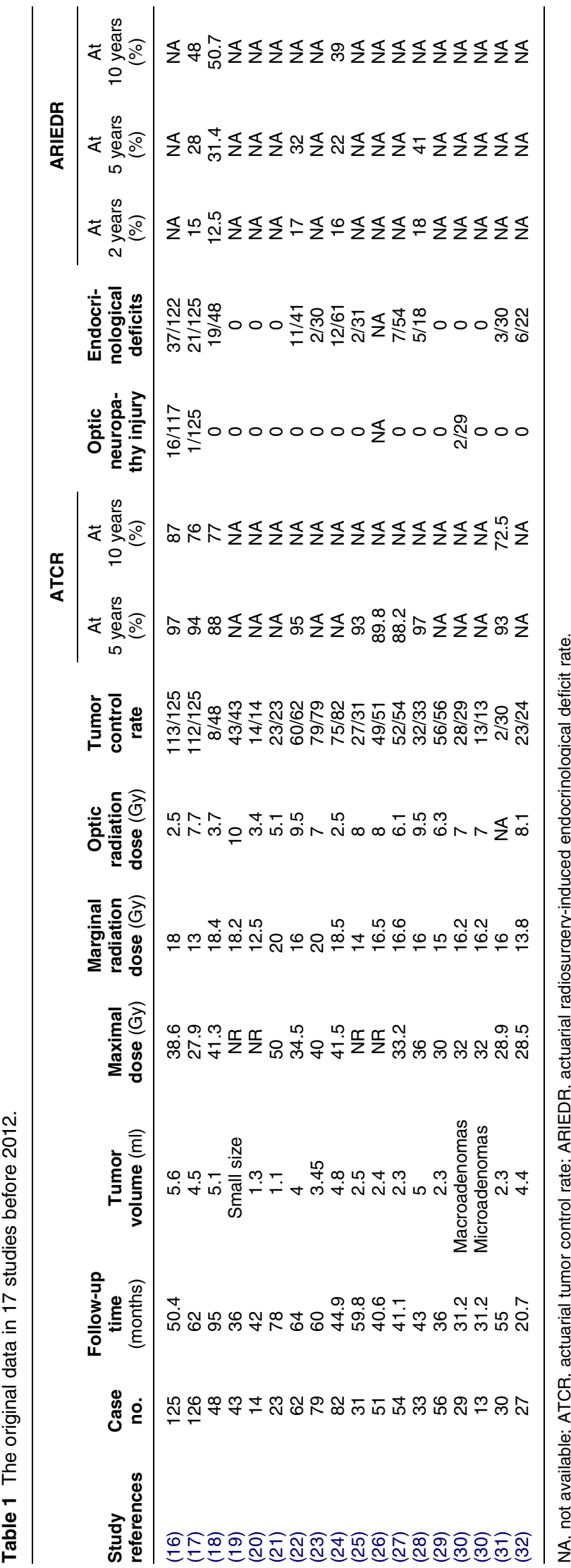

\section{Radiation dose and dose-related complications}

We analyzed the difference in doses among the three groups, including the maximal dose, the marginal radiation dose, and the optic radiation dose. There was no significant difference in radiation doses among the three groups (Supplementary Table 3, see section on supplementary data given at the end of this article).

The pooled maximal dose was 36 (95\% CI 32-39) Gy, the pooled marginal radiation dose was 17 (95\% CI 15-18) Gy, and the pooled optic radiation dose was 7 (95\% CI 06-08) Gy (Supplementary Figure $1 \mathrm{~A}-\mathrm{C})$. Based on the pooled maximal dose and the pooled marginal radiation dose, these studies were also divided into two groups respectively $(<36$ vs $\geq 36$ Gy and $<17$ vs $\geq 17$ Gy). A significant difference in endocrinological deficits was found between the two groups $(P<0.01$, Table 4). However, there was no significant difference in the tumor control rate between the two groups (Table 4).

\section{Quality of studies}

During the period of inclusion of patients ranging from 1987 to 2012, the Leksell Gamma Knife Unit model was different and included models U, B, C, 4C, and Perfexion. Neuroimaging and clinical follow-up were carried out in a different period. Additionally, the majority of studies did not provide adequate information or definition regarding pituitary insufficiency. The calculation of tumor volume among these studies was done using different methods. Lastly, the definition of the decrease or increase in size among these studies was not uniform (e.g. the volume change exceeded 10, 15, 20, 25, and $50 \%$ or a difference of $2 \mathrm{~mm}$ or more in multiple planes). The above-mentioned aspects might contribute to study inconsistency.

We carried out a sensitivity analysis by including five unqualified studies $(38,39,40,41)$ to determine whether the inclusion of these studies would affect the study conclusions (summarized in Supplementary Table 1). The pooled tumor control rate was 95\% (95\% CI 91-98\%); the pooled RRIONI was 5\% (95\% CI $2-10 \%)$; and the pooled RRIED was $4 \%$ (95\% CI $1-9 \%)$.

\section{Discussion}

\section{Principal findings}

To the best of our knowledge, this is the first systematic review on the efficacy of GKS for the treatment of NFPAs related to volumetric classification. Because different types of stereotactic radiotherapy as well as follow-up strategies for this condition lack evidence from randomized studies, the results of this meta-analysis will help clinicians make informed decisions as to which relative volumes of tumor treated with GKS had high tumor 
Table 2 Incidence of the efficacy parameters.

\begin{tabular}{|c|c|c|c|}
\hline & $\begin{array}{c}\text { Incidence (\%) } \\
\text { and } 95 \% \mathrm{Cl}\end{array}$ & $I^{2}(\%)$ & $\boldsymbol{P}$ \\
\hline \multicolumn{4}{|c|}{ Tumor control rate } \\
\hline Group I & $99(96-100)$ & $0(0 ; 0)$ & 0.9725 \\
\hline Group II & $96(92-99)$ & $66.8(21 ; 86.1)$ & 0.01 \\
\hline Group III & $91(89-94)$ & $22.3(0 ; 64.1)$ & 0.2521 \\
\hline Overall & $95(92-97)$ & $62.6(37.7 ; 77.5)$ & 0.0002 \\
\hline \multicolumn{4}{|c|}{ ATCR at 5 years } \\
\hline Group I & NA & NA & NA \\
\hline Group II & $91(88-93)$ & $0(0 ; 77.7)$ & 0.5594 \\
\hline Group III & $94(91-97)$ & $50.7(0 ; 81.9)$ & 0.0873 \\
\hline Overall & $93(90-95)$ & $42.7(0 ; 73.6)$ & 0.0827 \\
\hline \multicolumn{4}{|c|}{ ATCR at 10 years } \\
\hline Group I & NA & NA & NA \\
\hline Group II & NA & NA & NA \\
\hline Group III & $80(72-87)$ & $59.4(0 ; 88.4)$ & 0.085 \\
\hline Overall & $80(72-87)$ & $59.4(0 ; 88.4)$ & 0.085 \\
\hline \multicolumn{4}{|c|}{ Optic neuropathy injury } \\
\hline Group I & $1(0-4)$ & $0(0 ; 0)$ & 0.9725 \\
\hline Group II & $0(0-2)$ & $0(0 ; 0)$ & 0.9969 \\
\hline Group III & $2(0-5)$ & $79.5(60 ; 89.5)$ & $<0.0001$ \\
\hline Overall & $1(0-3)$ & $60(32 ; 76.5)$ & 0.0008 \\
\hline \multicolumn{4}{|c|}{$\begin{array}{l}\text { Endocrinological } \\
\text { deficits }\end{array}$} \\
\hline Group I & $1(0-4)$ & $0(0 ; 0)$ & 0.9725 \\
\hline Group II & $7(2-14)$ & $68.2(18 ; 87.7)$ & 0.0135 \\
\hline Group III & $22(14-31)$ & $79.4(59.8 ; 89.4)$ & $<0.0001$ \\
\hline Overall & $11(6-18)$ & $86.2(79.4 ; 90.8)$ & $<0.0001$ \\
\hline \multicolumn{4}{|c|}{ ARIEDR at 2 years } \\
\hline Group I & NA & NA & NA \\
\hline Group II & NA & NA & NA \\
\hline Group III & $16(13-20)$ & $0(0 ; 30.6)$ & 0.8783 \\
\hline Overall & $16(13-20)$ & $0(0 ; 30.6)$ & 0.8783 \\
\hline \multicolumn{4}{|c|}{ ARIEDR at 5 years } \\
\hline Group I & NA & NA & NA \\
\hline Group II & NA & NA & NA \\
\hline Group III & $31(25-37)$ & $54.9(0 ; 83.4)$ & 0.0644 \\
\hline \multirow{2}{*}{\multicolumn{4}{|c|}{ ARIEDR at 10 years }} \\
\hline & & & \\
\hline Group I & NA & NA & NA \\
\hline Group II & NA & NA & NA \\
\hline Group III & $49(44-55)$ & $0(0 ; 0)$ & 0.9117 \\
\hline Overall & $49(44-55)$ & $0(0 ; 0)$ & 0.9117 \\
\hline
\end{tabular}

NA, not available; ATCR, actuarial tumor control rate; ARIEDR, actuarial radiosurgery-induced endocrinological deficit rate.

control rates and low RRIONI and RRIED and which should be the best candidates for GKS.

In this study, NFPAs were divided into three groups according to the tumor volume at the time of treatment. In group I tumors with volumes ranging from 0 to $2 \mathrm{ml}$, the tumor control rate was $99 \%(95 \%$ CI $96-100 \%)$ and both the RRIONI and the RRIED were $1 \%(95 \% \mathrm{CI}$ $0-4 \%)$. It seems that the efficacy of GKS for the treatment of NFPAs is very nearly ideal. Our recent study (49) has found that the mean residual tumor volume doubling time of NFPAs is 3.4 years $(95 \%$ CI 2.4-4.5 years); that is, the majority of these tumors grow very slowly. The small-volume tumors in this group might not reach a large enough volume to impair patients' health during their lifetime, which would lead to an extensive and safe follow-up span. Furthermore, if the tumor volume increased to the volume of group II tumors, the rate of tumor control (RTC) with GKS was not significantly different from that observed for group I tumors. So, a comprehensive management plan of close follow-up and timely intervention is the optimal choice for these groups of NFPAs in order to minimize the side effects of radiation therapy. Because of the small volumes and slow growth rate, it is not necessary for group I patients to undergo GKS immediately after operation.

In group II tumors with volumes ranging from 2 to $4 \mathrm{ml}$, the tumor control rate was $96 \%$ (95\% CI 92-99\%) and the RRIONI and the RRIED were $0 \%(95 \%$ CI $0-2 \%)$ and $7 \%(95 \%$ CI $2-14 \%)$ respectively. This shows that the RTC is high and that the possibility of radiosurgeryinduced complications such as optic neuropathy injury and endocrinological deficits is low. GKS appears to be the optimal choice for the treatment of this mediumvolume group of NFPAs. 
Table 3 Pearson's $\chi^{2}$ test results for the comparative groups.

\begin{tabular}{lcc}
\hline Group & $\begin{array}{c}\text { Pearson's } \\
\chi^{2} \text { value }\end{array}$ & $\boldsymbol{P}$ \\
\hline Tumor control rate & 15.655 & $<0.001$ \\
Groups I vs II & 3.17 & 0.075 \\
Groups II vs III & 8.26 & 0.04 \\
Groups I vs III & 8.494 & 0.04 \\
Optic neuropathy injury & 12.056 & 0.002 \\
Groups I vs II & & \\
Groups II vs III & 8.809 & 0.003 \\
Groups I vs III & 3.297 & 0.069 \\
Endocrinological deficits & 49.082 & $<0.001$ \\
Groups I vs II & 6.801 & 0.009 \\
Groups II vs III & 25.645 & $<0.001$ \\
Groups I vs III & 27.288 & $<0.001$ \\
\hline
\end{tabular}

${ }^{\text {a }}$ Statistical significance is not available.

In group III tumors with volumes $>4 \mathrm{ml}$, the tumor control rate was 91\% (95\% CI 89-94\%), the RRIONI and the RRIED were $2 \%(95 \%$ CI $0-5 \%)$ and $22 \%$ (95\% CI 14-31\%) respectively, and the ATCRs at 5 and 10 years were 94\% (95\% CI 91-97\%) and $80 \%$ (95\% CI 72-87\%) respectively. The ARIEDRs at 2, 5, and 10 years were $16 \%$ (95\% CI 13-20\%), 31\% (95\% C: 25-37\%), and 49\% (95\% CI 44-55\%) respectively. With the increase in tumor volume, the RTC was significantly decreased and the RRIED was significantly increased. In addition, it seems that GKS may not have a long-term efficacy for the treatment of group III tumors and the RTC decreases with time. Furthermore, the ARIEDRs increase with time and reach values as high as $49 \%$ at 10 years. These results need to be confirmed by increasing the follow-up time and patient numbers.

\section{Effect of tumor volume to assess efficacy}

Some studies have found that tumor volume is the major factor predictive of tumor growth $(16,17,18)$. Gopalan et al. (18) found that tumor volume was a significant predictor of imaging outcome in long-term follow-up and tumor volumes $>5 \mathrm{ml}$ were significantly associated with a faster rate of tumor growth after GKS. Park et al. (17) found that larger tumors were more likely to progress. A target volume of $<4.5 \mathrm{ml}$ was an independent factor for a better progression-free survival. Starke et al. (16) reported that a tumor volume $>5 \mathrm{ml}$ was the only factor predictive of tumor growth in a multivariate analysis.

These data suggest that large tumors are more resistant to treatment with GKS. There are several reasons for the initial tumor volume influencing the outcomes of GKS in the treatment of NFPAs. For one thing, tumor volume may be a reflection of the involvement of the surrounding structures. Additionally, larger tumor volumes may reflect proximity to critical structures and make it difficult to deliver an ideal radiation dose to the target volume. In this meta-analysis, there was a significant difference in the tumor control rate and in the RRIED among the three groups. The reason for this might not be the radiation dose, because there was no significant difference in radiation doses among the three groups. This indicates that there is a statistical trend that the larger the tumor volume, the worse the control rate. Furthermore, the RRIED was significantly more common when there was an increase in tumor volume. However, there were radiation dose-related endocrinological deficits if the maximal dose or the marginal radiation dose was more than 36 or 17 Gy respectively.

\section{Effect of the radiation dose to assess efficacy}

A significant difference in endocrinological deficits was found between the two groups ( $<36$ vs $\geq 36$ Gy and $<17$ vs $\geq 17$ Gy). Previous reports have suggested that the radiation dose delivered to the pituitary stalk or functioning gland may be associated with radiosurgically induced hypopituitism $(50,51)$. The dose delivered to the pituitary gland is important, as it depends on the distance between tumor and pituitary gland, than on the marginal dose to the tumor. In the 17 studies, we did not find data about the radiation dose delivered to the pituitary gland; however, there was one report about the dose delivered to structures such as the oculomotor nerve and the brain stem (19). The reason for this might be the difficulty involved in defining the distance between the tumor and the pituitary gland because of their proximity. On the other hand, the definition of endocrine deficits in the majority of studies is 'a condition requiring hormone replacement' and the incidence of hypopituitarism is not assessable after GKS. Thus, the reported lower incidence of hypopituitarism after GKS compared with that observed after the use of other radiation techniques remains to be demonstrated.

The optic apparatus is generally believed to be the most radiosensitive to GKS. Recently, the dose threshold for the development of radiation-induced optic neuropathy has been questioned. Radiation tolerance for the optic nerve has been reported to range from 8 to $12 \mathrm{~Gy}$ and depends on the volume treated in single-dose radiosurgery $(52,53,54,55)$. Ideally, most studies suggest a maximum dose of $8 \mathrm{~Gy}$ and a minimum dose of 2-5 $\mathrm{mm}$ between the tumor and the optical apparatus to keep the risk of optic neuropathy close to

Table 4 Pearson's $\chi^{2}$ test results for the different dose groups.

\begin{tabular}{lcr}
\hline Group & $\begin{array}{c}\text { Pearson's } \chi^{2} \\
\text { value }\end{array}$ & $\boldsymbol{P}$ \\
\hline Tumor control rate & & \\
$<36$ vs $\geq 36$ Gy & 2.102 & 0.147 \\
$<17$ vs $\geq 17$ Gy & 0.174 & 0.677 \\
Endocrinological deficits & & \\
$<36$ vs $\geq 36$ Gy & 12.471 & $<0.001$ \\
$<17$ vs $\geq 17$ Gy & 8.316 & 0.004 \\
\hline
\end{tabular}


0 (56, 57). In our meta-analysis, the pooled optic radiation dose was 7 Gy (95\% CI 06-08), which may be the safe radiation dose threshold for the optic nerve.

\section{Limitations}

From Table 1, it becomes evident that the average duration of follow-up in all studies is limited to only 20.7-95 months after GKS (49.49 \pm 18.19 months, mean 4.12 years). This indicates that a mean follow-up period of $\sim 4-5$ years is, therefore, sufficient to outline the results of GKS in the short term and midterm, but real control of tumor growth in the long-term necessitates the continuation of the follow-up of these patients. The same caveat holds true for some side effects of GKS, in particular, the probability of new pituitary insufficiency seems to increase with time after GKS.

On the other hand, the nonrandomized, observational nature of the available literature is associated with several methodological issues, including publication bias, reporting bias (not all the outcomes were reported in all the papers), and lack of standardization in the study design (34). These issues highlight the inherent limitations in any meta-analysis based on observational data and the need for future large prospective studies.

\section{Clinical implications}

In light of very low-quality evidence (35) and the resulting uncertainty, it is suggested that clinical studies on this issue be prospective and use clear and explicit criteria for inclusion, objective outcome definitions and assessment, and uniform follow-up. Four suggestions should be considered: first, neuroimaging and clinical follow-up should be carried out at 6-month intervals for the first 2 years and yearly thereafter $(19,22,28)$, and long-term follow-up is necessary; second, uniform calculation of tumor volume and the Leksell Gamma Unit model are needed; third, a standard definition of pituitary insufficiency and the decrease or increase in size should be used; and lastly, NFPAs should be resected to the maximum extent during the operation in order to reduce the residual tumor volume to $<4 \mathrm{ml}$.

\section{Conclusion}

NFPAs, according to the tumor volume at the time of treatment, need stratification for GKS treatment. According to the small volumes and slow growth rate of group I NFPAs, comprehensive treatment including close follow-up and timely intervention is the reasonable choice in order to further optimize the risk:benefit ratio of GKS. GKS is the optimal choice for the treatment of group II NFPAs. The optimal treatment strategy for group III patients is still a challenge. Clinicians are suggested to remove tumor volume to the maximum extent during the operation in order to reduce the residual tumor volume to $<4 \mathrm{ml}$, by which patients will further benefit from the postoperative GKS treatment.

\section{Supplementary data}

This is linked to the online version of the paper at http://dx.doi.org/ 10.1530/EJE-13-0400.

\section{Declaration of interest}

The authors declare that there is no conflict of interest that could be perceived as prejudicing the impartiality of the research reported.

\section{Funding}

This work was supported by the National Natural Science Foundation of China (grant number 81271523, 2012), the Zhejiang Provincial Natural Science Foundation of China (grant number R2091137, 2010), and the Zhejiang Provincial Program for the Cultivation of High-level Innovative Health talents.

\section{Acknowledgements}

The authors are grateful to Edward Laws (Department of Neurosurgery, Brigham and Women's Hospital, Boston) for his critical evaluation and linguistic revision of this manuscript.

\section{References}

1 Laws ER Jr \& Vance ML. Radiosurgery for pituitary tumors and craniopharyngiomas. Neurosurgery Clinics of North America 1999 $10327-336$.

2 Gittoes NJ, Bates AS, Tse W, Bullivant B, Sheppard MC, Clayton RN \& Stewart PM. Radiotherapy for non-function pituitary tumours. Clinical Endocrinology 199848 331-337. (doi:10.1046/j.13652265.1998.00393.x)

3 Marcou Y \& Plowman PN. Stereotactic radiosurgery for pituitary adenomas. Trends in Endocrinology and Metabolism 200011 132-137. (doi:10.1016/S1043-2760(00)00242-3)

4 Laws ER Jr, Fode NC \& Redmond MJ. Transsphenoidal surgery following unsuccessful prior therapy. An assessment of benefits and risks in 158 patients. Journal of Neurosurgery 198563 823-829. (doi:10.3171/jns.1985.63.6.0823)

5 Alameda C, Lucas T, Pineda E, Brito M, Uria JG, Magallon R, Estrada J \& Barcelo B. Experience in management of 51 non-functioning pituitary adenomas: indications for post-operative radiotherapy. Journal of Endocrinological Investigation 200528 18-22.

6 Breen P, Flickinger JC, Kondziolka D \& Martinez AJ. Radiotherapy for nonfunctional pituitary adenoma: analysis of long-term tumor control. Journal of Neurosurgery $1998 \mathbf{8 9} 933-938$. (doi:10.3171/ jns. 1998.89.6.0933)

7 van den Bergh AC, van den Berg G, Schoorl MA, Sluiter WJ, van der Vliet AM, Hoving EW, Szabo BG, Langendijk JA, Wolffenbuttel BH \& Dullaart RP. Immediate postoperative radiotherapy in residual nonfunctioning pituitary adenoma: beneficial effect on local control without additional negative impact on pituitary function and life expectancy. International Journal of Radiation Oncology, Biology, Physics 200767 863-869. (doi:10.1016/j.ijrobp.2006.09.049)

8 Park P, Chandler WF, Barkan AL, Orrego JJ, Cowan JA, Griffith KA $\&$ Tsien $\mathrm{C}$. The role of radiation therapy after surgical resection of nonfunctional pituitary macroadenomas. Neurosurgery $2004 \mathbf{5 5}$ 100-106 (discussion 106-107). (doi:10.1227/01.NEU.0000126 885.71242.D7) 
9 Minniti G, Gilbert DC \& Brada M. Modern techniques for pituitary radiotherapy. Reviews in Endocrine \& Metabolic Disorders 200910 135-144. (doi:10.1007/s11154-008-9106-0)

10 Brada M, Rajan B, Traish D, Ashley S, Holmes-Sellors PJ, Nussey S \& Uttley D. The long-term efficacy of conservative surgery and radiotherapy in the control of pituitary adenomas. Clinical Endocrinology 199338 571-578. (doi:10.1111/j.1365-2265. 1993.tb02137.x)

11 Langsenlehner T, Stiegler C, Quehenberger F, Feigl GC, Jakse G, Mokry M, Langsenlehner U, Kapp KS \& Mayer R. Long-term follow-up of patients with pituitary macroadenomas after postoperative radiation therapy: analysis of tumor control and functional outcome. Strahlentherapie und Onkologie $2007 \mathbf{1 8 3}$ 241-247. (doi:10.1007/s00066-007-1706-1)

12 Minniti G, Jaffrain-Rea ML, Osti M, Cantore G \& Enrici RM. Radiotherapy for nonfunctioning pituitary adenomas: from conventional to modern stereotactic radiation techniques. Neurosurgical Review 200730 167-175 (discussion 175-176). (doi:10.1007/s10143-007-0072-x)

13 Ayuk J \& Stewart PM. Mortality following pituitary radiotherapy. Pituitary 200912 35-39. (doi:10.1007/s11102-007-0083-1)

14 Bulow B, Hagmar L, Mikoczy Z, Nordstrom CH \& Erfurth EM. Increased cerebrovascular mortality in patients with hypopituitarism. Clinical Endocrinology 199746 75-81. (doi:10.1046/j.13652265.1997.d01-1749.x)

15 Tomlinson JW, Holden N, Hills RK, Wheatley K, Clayton RN, Bates AS, Sheppard MC \& Stewart PM. Association between premature mortality and hypopituitarism. West Midlands Prospective Hypopituitary Study Group. Lancet 2001357 425-431. (doi:10.1016/S0140-6736(00)04006-X)

16 Starke RM, Williams BJ, Jane JA Jr \& Sheehan JP. Gamma Knife surgery for patients with nonfunctioning pituitary macroadenomas: predictors of tumor control, neurological deficits, and hypopituitarism. Journal of Neurosurgery 2012117 129-135. (doi:10.3171/2012.4.JNS112250)

17 Park KJ, Kano H, Parry PV, Niranjan A, Flickinger JC, Lunsford LD \& Kondziolka D. Long-term outcomes after gamma knife stereotactic radiosurgery for nonfunctional pituitary adenomas. Neurosurgery 201169 1188-1199. (doi:10.1227/NEU.0b013 e318222afed)

18 Gopalan R, Schlesinger D, Vance ML, Laws E \& Sheehan J. Longterm outcomes after gamma knife radiosurgery for patients with a nonfunctioning pituitary adenoma. Neurosurgery 2011 69 284-293. (doi:10.1227/NEU.0b013e31821bc44e)

19 Hayashi M, Chernov M, Tamura N, Nagai M, Yomo S, Ochiai T, Amano K, Izawa M, Hori T, Muragaki Y et al. Gamma knife robotic microradiosurgery of pituitary adenomas invading the cavernous sinus: treatment concept and results in 89 cases. Journal of NeuroOncology 201098 185-194. (doi:10.1007/s11060-010-0172-2)

20 Castro DG, Cecilio SA \& Canteras MM. Radiosurgery for pituitary adenomas: evaluation of its efficacy and safety. Radiotherapy and Oncology 20105109.

21 Hoybye C \& Rahn T. Adjuvant gamma knife radiosurgery in non-functioning pituitary adenomas; low risk of long-term complications in selected patients. Pituitary 200912 211-216. (doi:10.1007/s11102-008-0163-x)

22 Pollock BE, Cochran J, Natt N, Brown PD, Erickson D, Link MJ, Garces YI, Foote RL, Stafford SL \& Schomberg PJ. Gamma knife radiosurgery for patients with nonfunctioning pituitary adenomas: results from a 15-year experience. International Journal of Radiation Oncology, Biology, Physics $2008 \quad 70$ 1325-1329. (doi:10.1016/j.ijrobp.2007.08.018)

23 Liscak R, Vladyka V, Marek J, Simonova G \& Vymazal J. Gamma knife radiosurgery for endocrine-inactive pituitary adenomas. Acta Neurochirurgica 2007149 999-1006 (discussion 1006). (doi:10.1007/s00701-007-1253-7)

24 Mingione V, Yen CP, Vance ML, Steiner M, Sheehan J, Laws ER \& Steiner L. Gamma surgery in the treatment of nonsecretory pituitary macroadenoma. Journal of Neurosurgery $2006 \mathbf{1 0 4}$ 876-883. (doi:10.3171/jns.2006.104.6.876)
25 Iwai Y, Yamanaka K \& Yoshioka K. Radiosurgery for nonfunctioning pituitary adenomas. Neurosurgery $2005 \mathbf{5 6} 699-705$ (discussion 699-705). (doi:10.1227/01.NEU.0000156836.42945.28)

26 Picozzi P, Losa M, Mortini P, Valle MA, Franzin A, Attuati L, Ferrari da Passano C \& Giovanelli M. Radiosurgery and the prevention of regrowth of incompletely removed nonfunctioning pituitary adenomas. Journal of Neurosurgery 2005102 (Suppl) 71-74. (doi:10.3171/jns.2005.102.s_supplement.0071)

27 Losa M, Valle M, Mortini P, Franzin A, da Passano CF, Cenzato M, Bianchi S, Picozzi P \& Giovanelli M. Gamma knife surgery for treatment of residual nonfunctioning pituitary adenomas after surgical debulking. Journal of Neurosurgery 2004100 438-444. (doi:10.3171/jns.2004.100.3.0438)

28 Pollock BE \& Carpenter PC. Stereotactic radiosurgery as an alternative to fractionated radiotherapy for patients with recurrent or residual nonfunctioning pituitary adenomas. Neurosurgery 200353 1086-1091 (discussion 1091-1094). (doi:10.1227/01. NEU.0000088661.81189.66)

29 Petrovich Z, Yu C, Giannotta SL, Zee CS \& Apuzzo ML. Gamma knife radiosurgery for pituitary adenoma: early results. Neurosurgery $20035351-59$ (discussion 59-61). (doi:10.1227/01. NEU.0000068702.00330.47)

30 Sheehan JP, Kondziolka D, Flickinger J \& Lunsford LD. Radiosurgery for residual or recurrent nonfunctioning pituitary adenoma. Journal of Neurosurgery $200297408-414$. (doi:10.3171/jns.2002.97.6.1276)

31 Wowra B \& Stummer W. Efficacy of gamma knife radiosurgery for nonfunctioning pituitary adenomas: a quantitative follow up with magnetic resonance imaging-based volumetric analysis. Journal of Neurosurgery 200297 429-432. (doi:10.3171/jns.2002.97.4. 0785)

32 Mokry M, Ramschak-Schwarzer S, Simbrunner J, Ganz JC \& Pendl G. A six year experience with the postoperative radiosurgical management of pituitary adenomas. Stereotactic and Functional Neurosurgery 199972 (Suppl 1) 88-100. (doi:10.1159/000 056444)

33 Moher D, Liberati A, Tetzlaff J \& Altman DG. Preferred reporting items for systematic reviews and meta-analyses: the PRISMA statement. Journal of Clinical Epidemiology 200962 1006-1012. (doi:10.1016/j.jclinepi.2009.06.005)

34 Stroup DF, Berlin JA, Morton SC, Olkin I, Williamson GD, Rennie D, Moher D, Becker BJ, Sipe TA \& Thacker SB. Meta-analysis of observational studies in epidemiology: a proposal for reporting. Meta-analysis Of Observational Studies in Epidemiology (MOOSE) group. Journal of the American Medical Association $2000 \mathbf{2 8 3}$ 2008-2012. (doi:10.1001/jama.283.15.2008)

35 Swiglo BA, Murad MH, Schunemann HJ, Kunz R, Vigersky RA, Guyatt GH \& Montori VM. A case for clarity, consistency, and helpfulness: state-of-the-art clinical practice guidelines in endocrinology using the grading of recommendations, assessment, development, and evaluation system. Journal of Clinical Endocrinology and Metabolism 200893 666-673. (doi:10.1210/ jc. 2007-1907)

36 Fernandez-Balsells MM, Murad MH, Barwise A, Gallegos-Orozco JF, Paul A, Lane MA, Lampropulos JF, Natividad I, Perestelo-Perez L, Ponce de Leon-Lovaton PG et al. Natural history of nonfunctioning pituitary adenomas and incidentalomas: a systematic review and metaanalysis. Journal of Clinical Endocrinology and Metabolism 2011 96 905-912. (doi:10.1210/jc.2010-1054)

37 DerSimonian R \& Laird N. Meta-analysis in clinical trials. Controlled Clinical Trials 19867 177-188. (doi:10.1016/01972456(86)90046-2)

38 Martinez R, Bravo G, Burzaco J \& Rey G. Pituitary tumors and gamma knife surgery. Clinical experience with more than two years of follow-up. Stereotactic and Functional Neurosurgery 1998 70 (Suppl 1) 110-118. (doi:10.1159/000056413)

39 Hayashi M, Izawa M, Hiyama H, Nakamura S, Atsuchi S, Sato H, Nakaya K, Sasaki K, Ochiai T, Kubo O et al. Gamma knife radiosurgery for pituitary adenomas. Stereotactic and Functional Neurosurgery 199972 (Suppl 1) 111-118. (doi:10.1159/000 056446) 
40 Izawa M, Hayashi M, Nakaya K, Satoh H, Ochiai T, Hori T \& Takakura K. Gamma knife radiosurgery for pituitary adenomas. Journal of Neurosurgery 200093 (Suppl 3) 19-22.

41 Kobayashi T. Long-term results of stereotactic gamma knife radiosurgery for pituitary adenomas. Specific strategies for different types of adenoma. Progress in Neurological Surgery 200922 77-95.

42 Yoon SC, Suh TS, Jang HS, Chung SM, Kim YS, Ryu MR, Choi KH, Son HY, Kim MC \& Shinn KS. Clinical results of 24 pituitary macroadenomas with LINAC-based stereotactic radiosurgery. International Journal of Radiation Oncology, Biology, Physics 1998 41 849-853. (doi:10.1016/S0360-3016(98)00124-2)

43 Shin M, Kurita H, Sasaki T, Tago M, Morita A, Ueki K \& Kirino T. Stereotactic radiosurgery for pituitary adenoma invading the cavernous sinus. Journal of Neurosurgery 200093 (Suppl 3) 2-5.

44 Mitsumori M, Shrieve DC, Alexander E III, Kaiser UB, Richardson GE, Black PM \& Loeffler JS. Initial clinical results of LINAC-based stereotactic radiosurgery and stereotactic radiotherapy for pituitary adenomas. International Journal of Radiation Oncology, Biology, Physics 199842 573-580. (doi:10.1016/ S0360-3016(98)00256-9)

45 Muramatsu J, Yoshida M, Shioura H, Kawamura Y, Ito H, Takeuchi H, Kubota T \& Maruyama I. Clinical results of LINACbased stereotactic radiosurgery for pituitary adenoma. Nihon Igaku Hoshasen Gakkai zasshi 200363 225-230.

46 Kajiwara K, Saito K, Yoshikawa K, Kato S, Akimura T, Nomura S, Ishihara H \& Suzuki M. Image-guided stereotactic radiosurgery with the CyberKnife for pituitary adenomas. Minimally Invasive Neurosurgery 2005 48 91-96. (doi:10.1055/s-2004-830261)

47 Voges J, Kocher M, Runge M, Poggenborg J, Lehrke R, Lenartz D, Maarouf M, Gouni-Berthold I, Krone W, Muller RP et al. Linear accelerator radiosurgery for pituitary macroadenomas: a 7-year follow-up study. Cancer $2006 \mathbf{1 0 7} 1355-1364$. (doi:10.1002/ cncr.22128)

48 Iwata H, Sato K, Tatewaki K, Yokota N, Inoue M, Baba Y \& Shibamoto Y. Hypofractionated stereotactic radiotherapy with CyberKnife for nonfunctioning pituitary adenoma: high local control with low toxicity. Neuro-Oncology $201113916-922$. (doi:10.1093/neuonc/nor055)

49 Chen Y, Wang CD, Su ZP, Chen YX, Cai L, Zhuge QC \& Wu ZB. Natural history of postoperative nonfunctioning pituitary adenomas: a systematic review and meta-analysis. Neuroendocrinology 201296 333-342. (doi:10.1159/000339823)
50 Feigl GC, Pistracher K, Berghold A \& Mokry M. Pituitary insufficiency as a side effect after radiosurgery for pituitary adenomas: the role of the hypothalamus. Journal of Neurosurgery 2010113 (Suppl) 153-159.

51 Vladyka V, Liscak R, Novotny J Jr, Marek J \& Jezkova J. Radiation tolerance of functioning pituitary tissue in gamma knife surgery for pituitary adenomas. Neurosurgery $2003 \mathbf{5 2}$ 309-316 (discussion 316-317). (doi:10.1227/01.NEU.00000 43709.53906.31)

52 Leber KA, Bergloff J, Langmann G, Mokry M, Schrottner O \& Pendl G. Radiation sensitivity of visual and oculomotor pathways. Stereotactic and Functional Neurosurgery 199564 (Suppl 1) 233-238.

53 Leber KA, Bergloff J \& Pendl G. Dose-response tolerance of the visual pathways and cranial nerves of the cavernous sinus to stereotactic radiosurgery. Journal of Neurosurgery $1998 \mathbf{8 8} 43-50$. (doi:10.3171/jns.1998.88.1.0043)

54 Tishler RB, Loeffler JS, Lunsford LD, Duma C, Alexander E III, Kooy HM \& Flickinger JC. Tolerance of cranial nerves of the cavernous sinus to radiosurgery. International Journal of Radiation Oncology, Biology, Physics 199327 215-221. (doi:10.1016/ 0360-3016(93)90230-S)

55 Mayo C, Martel MK, Marks LB, Flickinger J, Nam J \& Kirkpatrick J. Radiation dose-volume effects of optic nerves and chiasm. International Journal of Radiation Oncology, Biology, Physics 2010 76 S28-S35. (doi:10.1016/j.ijrobp.2009.07.1753)

56 Sheehan JP, Niranjan A, Sheehan JM, Jane JA Jr, Laws ER, Kondziolka D, Flickinger J, Landolt AM, Loeffler JS \& Lunsford LD. Stereotactic radiosurgery for pituitary adenomas: an intermediate review of its safety, efficacy, and role in the neurosurgical treatment armamentarium. Journal of Neurosurgery $2005 \mathbf{1 0 2}$ 678-691. (doi:10.3171/jns.2005.102.4.0678)

57 Thoren M, Hoybye C, Grenback E, Degerblad M, Rahn T \& Hulting AL. The role of gamma knife radiosurgery in the management of pituitary adenomas. Journal of Neuro-Oncology 200154 197-203. (doi:10.1023/A:1012926022229)

Received 12 May 2013

Revised version received 13 July 2013

Accepted 31 July 2013 